\title{
Economic Activities Under Uncertainty: The Difference Between Speculation, Investment and Gambling
}

\author{
Raphael Max ${ }^{1}$, Alexander Kriebitz ${ }^{1} \&$ Christoph Luetge ${ }^{1}$ \\ ${ }^{1}$ TUM School of Governance, Technical University of Munich, Munich, Germany \\ Correspondence: Raphael Max, TUM School of Governance, Technical University of Munich, Munich, \\ Germany, Arcisstr. 21, 80333 Muenchen, Germany. E-mail: r.max@tum.de
}

Received: November 20, 2019

Accepted: December 22, 2019 Online Published: January 20, 2020

doi:10.5539/jms.v10n1p28

URL: https://doi.org/10.5539/jms.v10n1p28

\begin{abstract}
In the ethical discourse about financial markets, the terms "investment", "speculation" and "gambling" often seem confusing and lack a clear distinction. The inconsistent use of this terminology has concrete consequences for the public perception. We attempt to establish a concept which draws a clear line between these activities and can serve as a baseline for discourse about how to assess investment, speculation and gambling on a normative level. We analyze existing literature and develop a conceptual framework to provide an overview of the differences between investment, speculation and gambling. We conclude that gambling differs structurally from investment and speculation in terms of the classic distinction between risk and uncertainty and the separation between consuming and non-consuming activities. Moreover, we arrive at the conclusion that investment and speculation share too many similarities to be separated in a consistent way.
\end{abstract}

Keywords: investment, speculation, gambling, uncertainty

\section{Introduction}

Are speculators thieves, and investors angels? Is gambling per se morally wrong? Why do we "invest" in our human capital but never use the verb "speculate" in connection with human capital? The normative assessment of investment, speculation and gambling has a rich tradition and dates back to antiquity. A majority of observers accept the communality of investment, speculation and gambling, and the fact that the outcome of these economic activities is unknown ex-ante, whereas the differences between investment, speculation and gambling remain disputed, controversial and often inconsistent. The insufficient clarity concerning the boundaries of these financial activities influences our perception: Academic papers and journalistic articles alike regard speculation and gambling as a moral problem, but often fail to provide consistent definitions of what they define as "speculation" (Sandel, 2013; Krugman, 2009). Journalists, NGOs and politicians label gamblers and speculators as "irresponsible", "uncaring renegades" or "locusts", whereas the term "investor" designates a prudent economic actor who adds a value to the social good. A brief look at Goethe's Faust, Dostoyevsky's "The Gambler" and Pushkin's "The Queen of Spades" reveals that this perception is not a novelty, but rather an old stereotype. When analyzing the historic perception of economic activities under uncertainty, we find that the contemporary discourse mainly focuses on financial markets. In this sense, the debate seems to fall short, as economic actions under uncertainty in fact encompass all sectors of the economy.

As public opinion and legislation depends on clear definitions, we concentrate on the task to disentangle investment, speculation and gambling. If scholars and ethicists aim to improve public discussion and provide findings in order to advance regulation, they need to provide clear definitions and dispose of distorted definitions (cf. Szado, 2011). Although, several scholars before us have concerned themselves with finding definitions for investment, speculation and gambling, we still lack an elaborated framework to define and to characterize financial activities. Therefore, the aim of this conceptual paper is to analyze how scholars differentiate between those concepts, highlight weaknesses of previous concepts, formulate our own approach and provide a consistent basis for normative assessment.

\section{Historical Background}

In the following part, we argue that the critique of profit maximization, based on the philosophy of the pre-modern era, the concept of a just price (cf. Luetge, 2015) and the rejection of gambling activities constitute the fundament 
of the widespread negative perception toward economic activities under uncertainty. Although we find the earliest distinction between investment, speculation and gambling in Joseph de Vegas' Confusions of Confusions in 1688, the genealogy of moral and immoral forms of financial activities dates back to Plato and Aristotle. In general, both philosophers had a critical perception of financial activities, as they regarded profit-maximization as detrimental to the eudemonia of the individual and the polis alike. In The Republic, Plato related profit-orientation with the lowest social class, which represents the domain of lust in human soul, and defined justice as fulfilment of the individual duty for the society. Plato regarded individual profit-maximization as harmful to society, as it alters the wealth and income distribution of the polis and distracts citizens from politics. Likewise, Aristotle argued that profit maximization is the wrong motivation for economic activities and distinguished between two forms of economic activities: Oikonomike and chremastike (Aristotle, 1920). Economic activities falling into the first category aim at satisfying basic needs, whereas economic activities fall into the category of chremastike aim at maximizing profits. Aristotle saw the latter in a bad light and discouraged them for the same reasons as Plato (Aristotle, 2009). In ancient Rome, which was under strong Platonic, Aristotelian and Stoic influence, a similarly strong attitude against risk and uncertainty prevailed (cf. Cato, 2014; Cicero, 1913).

Based on Marx's reflections on speculation, Vladimir Lenin later called on speculators to be shot, as he perceived speculation as a typical phenomenon of bourgeois capitalism leading to the expropriation of the working masses (Volkogonov, 1994).

Unlike criticism of profit-maximization, gambling was primarily discouraged as it causes moral corruption and to a lesser extent because of adverse social or political consequences. Moreover, the perception of gambling varied throughout cultures and ages. In ancient Rome, gambling was even commercialized and regulated by law. However, the assessment of gambling changed after the advent of the world religions. Muslim (cf. IbnTaymiah, 1994; Murphy \& Smolarski, 2017) and Christian scholars heavily criticized the practice of gambling, as it distracts people from productive activities and worship to God. Augustine called gambling an invention of the devil, a view which shaped centuries and influenced even modern politicians such as George Washington (Lutzer, 2001).

Analyzing the traditional moral perception of economic activities under uncertainty, we find that the critique of speculation in financial markets originates from the rejection of profit-maximization and gambling as well as the concept of a just price. Accordingly, opponents of speculation argue that it fosters a culture of greed and that speculation distorts prices, which in turn causes negative consequences for the economy. The criticism of gambling mainly originates from a rejection of risk-taking and the fear that it morally corrupts individuals.

\section{Time-Consistency of Categorization}

As stated above, the categorization of investment, speculation and gambling often leads to the situation that we treat similar actions differently. One important factor in the classification of financial actions seems to be their success, which results in the paradoxical situation that the press and academia label successful trades as investments while calling significant losses gambling or speculation. Examples of headlines of this type include: "The City trader accused of fraudulently gambling away 1.4bn GBP of his bank's money" (Neate, 2012) or "Bankrupt builder imprisoned after gambling away 1.5m USD" (Radio NZ, 2018). If the actions of the economic actors had had a positive outcome, the headlines would have probably been different. In the event of a profit, the "City trader" and the "bankrupt builder" would probably have been called successful investors. Following our hypothesis that different categorizations result in different perception and actual policy implications, the process and durability of the categorization is of significant importance. Hence, we argue that the assessment of an economic action ought to be equal ex-ante and ex-post. This means that we suggest not to classify financial activities by criteria, which change over time, but to search for inherent differences instead, which do not depend on the settings of the action. Hence, the characteristics of gambling, speculation and investment need to be based on inherent and not on accidental properties (cf. Brennan \& Jaworski, 2015).

Moreover, the classification of purchasing a share needs to be consistent before and after purchase, regardless of the success or failure of the decision. Based on our argumentation that the assessment of economic actions ought to be equal ex-ante and ex-post, we conclude that the differences between the categories must be embedded in a deeper structure, and be determined based on our ex-ante knowledge of the characteristics of an action. These characteristics will be discussed in the following sections.

\section{Why Gambling is Different}

The American psychologist John B. Watson (2012) claimed, "stock gambling is about the only thing that offers the same kind of thrill that big game hunting does and you can play the market right at your desk." We argue that neither the idea of gambling in stock markets nor the comparison of stock trading and big game hunting are helpful for the debate on financial markets, as gambling fundamentally differs from speculation and investment. In 
contrast to investment and speculation, gambling is a consuming activity and not subject to genuine uncertainty.

In our view, the main difference between gambling and other forms of economic activities lies in the separation of uncertainty and risk. In his famous treatise Risk, Uncertainty and Profit, Frank Knight (1921) distinguished between two types of uncertainty. The first type, which he calls "risk", describes the situation when we know the potential outcomes and even their odds in advance. This form of risk typically occurs when we roll the dice or use slot machines and other variations of random generators. The commonality between these activities is not only that we can determine the probabilities of each event ex-ante, but that we can even calculate expected values. In contrast to risk, however, genuine uncertainty describes the situation where the probabilities are unknown ex-ante. Accordingly, uncertainty occurs in complex systems where many actors interact over time, such as the stock market, and where the outcomes depend on many different factors. In this case, we neither know the probabilities for certain events, nor can we clearly delimit the range of possible outcomes. Likewise, the success of currency trading on the day prior to the Brexit vote also depended on an infinite number of factors and probabilities, which in sum could not be quantified appropriately ex-ante. Since it is impossible to quantify uncertainty prior to the purchase of shares or real estate, investment and speculation constitute economic activities without measurable risks. Accordingly, rolling the dice and staking money in property differ in terms of complexity, as the success of investment and speculation depends on more than one factor, whereas gambling purely depends on chance.

The separation between uncertainty and risk also has an implication for the division between consuming and non-consuming activities. This classification originates from Keynes, who classified all economic decisions as "consumption" or "investment" (Keynes, 1936). In order to prevent conflation with our own understanding of investment, we have decided to use the term "non-consuming activities" instead of "investment". While "consuming activities" refer to utility maximization, "non-consuming activities" relate to profit-maximization. Since there is no rationally expectable long-term benefit in gambling - at least for the gambler-many authors describe gambling as a form of consumption (cf. Emery, 1896). While gamblers seek entertainment, pleasure or "thrill", investors and speculators rationally aim at maximizing their profit by delaying consuming activities (cf. Watson, 2012). Arthur (2000) argued in a similar way and defined gambling as a consumer activity and investment as a producer activity. According to Borna and Lowry (1987), gambling cannot take place under the assumption of strictly rationally acting individuals as the outcome is pure chance and the players will usually lose on average against the provider of the game. In a nutshell, gambling only makes sense if you are gambling in order to enjoy your leisure time. The etymology of the term "gambling" in the Germanic languages (Middle English: gamenen = to play, German: zocken (West Yiddish: skhoken = to play)) and in the Romance languages (e.g., Spanish: jugar juegos de azar; Italian: giocare d'azzardo; French: jouer à des jeux d'argent) seems to confirm our view.

What does this imply for the usage of the term "gambling" in financial markets? The comparison of certain activities in financial markets with gambling implies that financial markets are a zero-sum game. However, this argumentation seems to the neglect the peculiarities of gambling, the classification of consuming and non-consuming activities as well as the conceptualization of uncertainty. In situations where risks can be quantified ex-ante such "as rolling the dice", it is impossible to maximize profits, as the outcomes are determined by chance and not by individual skills or knowledge. As shown above, expecting to become a millionaire by rolling the dice one million times is irrational. However, profit maximization is possible in the face of uncertainties, and can create positive externalities. Knight (1921) argued that real opportunities for profit and win-win situations can only arise in the face of genuine uncertainty, while Schumpeter (1942) has labelled uncertainty as a driver for the economy and called it a process of "creative destruction". Sinn (1986) even defines uncertainty as a production factor and concludes that well-organized hedging always increases productivity (cf. Nell, 1990). In the case of uncertainty, it is not only possible to maximize profit, but also to create positive externalities, such as inventions and innovations. In the case of gambling, however, there are no externalities inherent to gambling per se. Therefore, the comparison of financial markets is not an apt description of reality, as players in financial markets strive to make profit based on theoretical assumptions of future developments and create spill-overs for other market participants. Based on this argument, we conclude that oft-stated political claims such as "Stop Wall Street Gambling!" are misleading and not helpful for improving financial markets and decreasing systemic risks.

Finally, the conceptual differences between gambling and transactions on the financial markets also affect the question of how to limit financial markets. While regulations on gambling naturally focus on the gambler, the laws concerning financial markets refer to the common good.

\section{Investment and Speculation}

In the previous section, we dealt with the conceptual differences between gambling and other forms of economic activities. In the following section, we will examine the question of how to separate speculation from investment 
and whether a distinction between the two financial activities is at all possible. Therefore, we evaluated the literature, (e.g., Arthur, Williams, \& Delfabbro, 2016; Allen, 1952; Angel \& McCabe, 2009; Borna \& Lowry, 1987; Holliday \& Fuller, 1974; Williams, Volberg, Stevens, Williams, \& Arthur, 2017), collected the most common distinguishing features and checked them for consistency.

However, before we come to the conceptual differences between investment and speculation, we will examine their communalities. The shared principle of speculation and investment is that people are staking money by delaying consuming activities in the hope of future gains. Linguistic evidence seems to back up our assumption that investment and speculation share more similarities between each other than gambling. In Chinese, Korean and Japanese for example, speculation (C: 投机 / K: 투기 / J: 投機) and investment (C: 投资 / K: 투자 / J: 投資) share the same initial character with the meaning to throw or stake, which hints at major similarities in the two concepts, whereas the words for gambling do not (C: 奢博 / K: 도박 / J: 賭博). Accordingly, speculation and investment alike refer to the staking of money in the hope of future gains. However, where should one draw the line between investment and speculation? The concepts of investment and speculation have to be understood as ideal types in the sense of Weber (1976), as there is no such thing as perfect investment or perfect speculation.

In the following paragraphs, we list several oft-recurring arguments as to how investment and speculation could be differentiated. The arguments are concerning the expected time frame of an economic activity, the risk exposure and expected rate of return, the costs and effort of the decision-making process, the amount and origin of the funds, the economic utility of the action, the type of the underlying asset and the interest in the underlying asset.

\subsection{Expected Time Frame of an Economic Activity}

The vast majority of literature agrees that investment and speculation differ over the projected timeframe (e.g., Bunia, 2013; Bogle, 2012; Granero et al., 2012; Krugman, 2009; Graham \& Dodd, 1934; Graham, 2009; Angel \& McCabe, 2009). The idea of separating speculation and investment by duration has even entered financial market legislation. In some countries (cf. German Income Tax Act \$23), the tax rate on capital gains depends on a diminishing scale regarding the holding period of assets. According to this perception, preparing long-term business projects is of a different nature to arranging intraday trades. While investment is typically associated with a long-term horizon and a sophisticated preparation, many observers view speculation as a short-term action. Bunia (2013) characterizes investment as having a long-time horizon and a concentration on real values, whereas a speculator merely makes use of short-term "irreal" deviations in actual market equilibria to make profits. Arthur et al. (2016) claim that most forms of investment are held for at least a matter of months or even years, and that speculation has a varying time horizon depending on the type of activity. The same applies to the actors: Speculators are generally accused of only being interested in short-time profit, whereas investors are following long-term goals (e.g., Granero et al., 2012; Krugman, 2009; Graham \& Dodd, 1934; Angel \& McCabe, 2009).

Although we regard the period of holding an asset as an important question, we refute the traditional view that time is a criterion to be used to distinguish between speculation and investment. The first concern is that we lack objective criteria for drawing the line. How long do you have to hold an asset in order to become an investor? More than a second? A day? A week? Months? A year? Our second concern is that the period of holding an asset might depend on the asset itself or the way it is traded. Finding the right period to distinguish between investment and speculation seems to be arbitrary, as the action might depend on constraints which are not specific to investment or speculation per se, but depend on the asset, the business sector or on how the market is structured. However, these constraints are not inherent to speculation. Our third concern is that the expected time frame of an acquisition may change over time, and hence cannot be assessed objectively ex-ante. The shortcomings of the classical definition become evident when it comes to hedging: Is it speculation if a corporation in the energy sector which has acquired futures in crude oil in order to hedge price fluctuation with the intention of holding the position for several months, sells their futures after only one day due to unexpected profits? Does a fund which usually only holds position for five years or longer - and hence is commonly seen as an investor - become a speculator if it is hedging economic risk overnight, or is it both?

In such cases, the classic definitions of speculation and investment fail to capture the structure of the problem and might even create a wrong perception. Moreover, a solid distinction allowing the development of a normative basis of economic actions ought to be based on a more sophisticated concept and clear rules.

\subsection{Risk Exposure and Expected Rate of Return}

Another perseverative argument found in literature is that speculation and investment diverge in terms of risk exposure (e.g., Arthur et al., 2016; Shin, Choi, Ha, Choi, \& Kim, 2015; Graham \& Dodd, 1934; Graham, 2009). Traditionally, observers (Shin et al., 2015) associate speculation with a high risk and excessive profits, whilst perceiving investment as a financial activity with a low risk exposure. 
Our first concern in differentiating between speculation and investment according to the risk exposure relates to the question of economic abstention. As Luhmann (1991) described, not deciding or explicitly deciding not to participate in economic actions bears huge risks as well. Luhmann's argument is a convincing one due to its practical relevance. Not investing money in times of inflation might have similar consequences to buying a share, which then declines in value. However, the costs of economic abstention appear to be hidden and economic abstention can impose high opportunity costs on individuals.

Our second argument concerns the separation between risk and uncertainty itself. In our view, the aforementioned argumentations of disentangling investment and uncertainty commit the same fallacy - the lack of separation between risk and uncertainty. Before, we delve deeper into our argument; we need to clarify the object of our observation, namely risk and uncertainty. Etymologically, "uncertainty" and "risk" are closely related and regularly confused. Many argue that the word "risk" can be derived from the ancient Greek word for "cliff". In Chinese, "risk" can be derived from the character for wind. Wind and cliffs represent danger and uncertainty, as sailors were often not able to foresee cliffs, due to poor visibility during a storm. From a historical and philosophical point of view, the ideas of risk and uncertainty were connoted to naval matters, which coined the understanding of uncertain economic activities (Cato, 2014). By the 20th century, the terms "uncertainty" and "risk" had become a major focus for economists. As stated above, according to Knight (1921), uncertainty and risk are two different concepts. While risk refers to uncertainty which is quantifiable such as rolling the dice, uncertainty proper describes the situation where we are not able to know the percentage and the odds ex-ante. Based on Knight's division between risk and uncertainty, we conclude that there is no such thing as genuine risk in financial markets. The movement of a share price depends on an infinite number of parameters which the shareholder ultimately may not be aware of and cannot influence. The same holds for the successful purchase of a company. As it is impossible to give a success ratio for a given case, we are not able to calculate the risks and hence cannot differentiate between high-risk and low-risk. The difference between "investment" and "speculation" therefore cannot depend on the exposure to risk, as both activities fall under the umbrella of "uncertainty". As risk cannot be defined ex-ante, classifying economic actions by different levels of risk is not appropriate, in our view.

\subsection{Costs of the Decision Making}

Another criterion to distinguish between investment and speculation is the time and effort dedicated to preparations for the investment or speculation decision. The topic relates to the rationale of separating investment and speculation by the role of luck and skills. Many argue (e.g., Tracey, 1932), that investment decisions do not depend on luck, but on the skills and foresight of the "prudent" investor, whereas speculators solely depend on luck and chance (Bogle, 2012). The role of chance also plays a role in other approaches, which compare speculation with mathematics (Bogle, 2012) and (Vogl, 2010). According to this view, investment is associated with analyzing fundamentals and developing an extensive strategy, whereas speculation is regarded as mere observation of price movements, technical charts and, in the end, luck. Consequently, Granero et al. (2012) posit that speculators generally do not carry out risk analysis, which minimizes the effort and time spent on the decision-making process.

However, we do not regard the costs of decision as an apt criterion for delineating investment and speculation. Similar to the chapter where we concentrated on the "expected time frame of an economic activity" and the "risk exposure and expected rate of return", we regard the preparation time not as something specific to speculation or investment, but rather a characteristic of the asset. Betting on commodity prices requires, for example, a huge amount of time, and individuals have to be knowledgeable about political, macroeconomic and structural surroundings. At the same time, purchasing houses in order to re-sell them at a later period requires that individuals gather object specific information. Hence, distinguishing between investment and speculation in terms of preparation time seems to be arbitrary, as the action might depend on constraints which are not specific to investment or speculation per se, but on the asset, business sector, design of the market and the individual who decides how much time he will dedicate to his decision. The same applies to the proportion of luck and skills. Although successful investment decisions depend on foresight and skills, the role of chance or luck should not be underestimated. The terms "chance" and "risk" have a close linkage, as "chance" relates to events which are not controllable by the actor. Keynes' statement, that businesspersons play a game of skill and chance, seems to be an apt description of reality. Betting on falling oil prices - commonly perceived as speculation-requires individuals to know the structure of the oil market and political surroundings. The same holds for buying a house, which is regarded by many as a form of investment. Nevertheless, best knowledge cannot prevent unexpected outcomes - as we can only minimize uncertainty by collecting information - but can never displace it entirely.

\subsection{Amount and Origin of the Funds}

Another distinction between investment and speculation is the amount and origin of capital dedicated to the action. 
Borrowing funds to buy stocks or other assets is labelled speculative, while using one's own money is perceived as investment. In accordance with this view, an investor spreads his capital across various objects and avoids using a vulnerable amount of his available equity for his actions. Both concepts are two sides of the same coin, as they refer to the way the individual behaves in financial markets.

It is precisely on this point, where we raise our concerns, that we find the same difficulties as in the previous section. The question remains as to how to find the level of equity capital which serves as a threshold to separate speculation and investment. Moreover, the amount and origin of the funds is not a criterion specific to the action itself, but describes the circumstances under which the action is done. The same applies for the risk-diversification argument. The strategy of diversifying risks or hedging uncertainty more effectively, by buying different assets which do not depend on each other, is a prudent one. However, the distribution of resources is not a feature of the action but rather a mode of it. Consequently, an economic action may be "speculative" irrespective of the amount of money put into the speculation asset and of the way we arrange the assets, as both characteristics describe the way the action is done, but not the action itself. Nevertheless, the question of the amount and origin of the funds is important, and calls for an ethical assessment.

\subsection{Economic Utility}

In the following paragraph, we discuss whether it is possible to use economic utility or -as it is commonly called "added value" as a tool to separate "speculation" from "investment". According to many experts (e.g., Borna \& Lowry, 1987; Hazen, 2005; Holliday \& Fuller, 1974; Wahl, 2008), speculation diverges from investment in that it does not create a benefit for society. Generally, we find two subtypes of argument: For some, it is due to the speculation, which does not create an added value (Wahl, 2008); for others it is economic uselessness which separates gambling from investing and stock-market speculation (e.g., Borna \& Lowry, 1987; Hazen, 2005; Holliday \& Fuller, 1974).

The distinction between socially-beneficial economic activities has a rich history and is often based on a negative historical perception of certain economic activities. However, before we reflect on the characteristics of speculation and investment in this regard, we ponder how to determine the economic utility of economic actions. The ideas of Adam Smith, Vilfredo Pareto, John Rawls and many other philosophers provide us with a plethora of tools to normatively assess economic actions. According to Rawls (1971), economic actions should prioritize the interests of the least privileged members of the society. Following Pareto, economic activities should not harm anyone, but should contribute to the wealth of at least one person. Hence, determining the economic utility of certain economic actions depends on the assessment tools chosen for ethical assessment, and come to different conclusions. Under these circumstances, the definition of speculation and investment naturally differs from author to author. The confusion created by using normative criteria for describing and defining economic actions seems to be one of the main reasons why there is no consensus on speculation. As a result, the blurring of the lines between the normative and descriptive levels constitutes the main shortcoming of using added value as a method for distinguishing between speculation and investment.

\subsection{Type of the Underlying Asset}

In literature, we often encounter the position that investment and speculation differ in the nature and type of the asset (e.g., Arthur, 2000; Arthur et al., 2016). Some regard the purchase and sale of real estate as "investment" and the trading of derivatives or the participation in controversial markets or "sin-stocks" as "speculation" (cf. Moura-Leite, Padgett, \& Galan, 2014; Risi, 2018). Arthur et al. (2016), for example, posit the existence of "casino-type" products in stock markets.

Indeed, one is justified in asking what rationale lies behind the economic actions of an enterprise and which assets are being traded. However, the purchase of an asset can have completely different implications, depending on the actor, the market and the concrete situation. For some companies and individuals, hedging a currency position is important for economic survival, while for others it is a means of profit maximization. A good example is the situation prior to the Brexit vote, when many companies had to decide whether to buy or to sell British pounds. In this concrete scenario, the choice of the asset itself depended on a broad spectrum of factors, such as expectations about the future, interdependencies and preferences. The asset is not a criterion which refers to the action per se, and consequently not an inherent element of speculation. If we used the asset as the baseline for separating speculation and investment, this would say more about the asset than about the action. This understanding, however, does not get to the heart of the matter and contradicts our use of language too strongly.

Nevertheless, this does not mean that it is irrelevant whether hedge funds buy real estate or government bonds, as the unregulated acquisition of real estate by single market participants might indeed lead to a distortion of the market. 


\subsection{Interest in the Underlying Asset}

Is the purchase of bottles of wine without the intention to drink them speculation? In the final section, we discuss the argument as to whether interest in the underlying asset is an apt criterion to distinguish between speculation and investment. According to many observers (Yeo, 2017; Bogle, 2012; Graham, 1958), speculation and investment diverge where it comes to the interest in the underlying asset. Prominent proponents of this view include Benjamin Graham, Warren Buffet and other representatives of value investing. Typically, they perceive investment as an action "where you look to the asset itself to determine your decision to lay out some money now, to get some more money back later on" (Yeo, 2017). In contrast, they regard speculation as an operation without any emotional relationship between buyer and asset, and accuse speculators of solely focusing on the price. The differentiation between intrinsic and extrinsic value, which we attribute to Aristotle, Kant and Marx, has influenced this perception. According to Aristotle, prices are extrinsic values, which change through sudden changes of demand and supply. This matters for defining speculation and investment, as speculators are believed to bet on the price while investors are mainly interested in the growth of the (intrinsic) value of a good.

However, we identify several shortcomings of this concept: Its first weakness is practicability. The intentions behind economic activities are difficult or even impossible to measure. Purchasing shares in a blue-chip company might indicate that the person is interested in possessing a part of this company. However, we could also explain his or her action as mere profit maximization. From an outsider's perspective, it is difficult to judge who is an investor and who is not, because disentangling the intention of maximizing profits and the wish to possess a specific asset appears to be impractical.

Alongside to the practicability argument, we have a theoretical concern, as the motivations behind economic actions may change over time. How can we classify an economic activity if the intention behind the purchase of a share is the wish to support a specific enterprise, but the motivation to sell is it later driven by profit maximization? The buyer of a house might firstly be interested in possessing the underlying asset, without having the explicit intention of selling it at a later point in time. Being offered twice the original price may tempt him to sell the house immediately. Likewise, an individual who acquired a large amount of blue chip-shares for emotional reasons, is naturally inclined to see the stock value of his shares rising. The main problem here is that the motive of profit maximization might gain importance after the purchase of the share, and that outside factors such as sudden price changes have an effect on the motivations of the individual. What does this tell us about the difference between speculation and investment? It tells us that intentions alter over time, as the decision-making process itself depends on relative prices and are unforeseeable ex-ante. The prevalence of unstable motivations, finally, violates the principle of time consistency, as the ex-ante and ex-post analysis could become unstuck.

With the third weakness, we intend to foreclose a link to the normative assessment of economic activities under uncertainty. The focus on motivation and "goodwill" suggests that the separation of investment and speculation is a deontological concept. Using a normative criterion, however, blurs the lines between investment and speculation. As observers need to judge the motivations of the acting individual, they might come to different conclusions and evaluate the same action differently. Moreover, a consequentialist would argue that the effect of an economic activity would not depend on the intentions the economic actors are following. In his or her view, the effect of an acquisition by an actor who is himself/herself interested in the underlying is exactly the same as an acquisition by an actor merely following the intention to profit from price movements. The problem is therefore that the divergence between speculation and investment depends on the eye of the beholder and is therefore subjective.

These shortcomings force us to the conclusion that a normative assessment should be based on more solid distinction, which hinges on objective criteria and not on a normative concept.

\section{Is "Investment" Just a Euphemism?}

Concluding our arguments above, we find that all the criteria we have examined appear not to be sufficient to draw a clear line between investment and speculation, but rather confuse the object of observation. But why do we propose to label economic activities under uncertainty as "speculation"?

We argue that the term "investment" has a relatively positive connotation, which suggest that the action is secure, foreseeable and controllable. However, investors face the same dilemma of not knowing the future, like speculators. Another reason is language. Historically, the word "speculation" originated from the Latin word speculari, and had the meaning of "a vague guess" and related to the future. In everyday language, we often refer to claims which seem doubtful as "pure speculation". Speculation however is different from knowledge, as knowledge relates to facts. The same holds for economic actions. Although we are knowledgeable about basic economic laws and have developed a great understanding of economics, we still struggle to predict even short-time developments. Why is this the case? Normally, laws in social science are based on the assumption of ceteris 
paribus. We are often analyzing actions under the condition that nothing else changes. This is of course an important precondition for elaborating models, but the main reason why practice and theory often fall apart. The application of these theories to economic decisions therefore comes up against many natural constraints. Betting on prices is in fact even more difficult, as we have many variables which influence the outcome. The value of a house might be determined by factors such as immigration, social stratification, political decisions and even climate change. One of these variables can suddenly change the entire situation. As a result, we cannot know what will happen in future but rather guess, sometimes based on experience, sometimes based on logics, but in the end, we do not know the results.

\section{Conclusion}

Following a review of the historical background and the description of the importance of time-consistent categorizations, we dealt with the demarcation of gambling, investment and speculation. Based on our consideration, we derived following two conclusions:

The fundamental peculiarity of gambling is that it involves actions where uncertainty can be quantified ex-ante. The classic example is throwing a dice and betting on a certain number. Actions of this kind can be reduced to consumer decisions, as expecting long-term profit from dice games is irrational. In contrast, speculation and investment describe forms of actions under genuine uncertainty. This type of uncertainty is not quantifiable, since the number, selection and weight of the individual influencing variables are unknown ex-ante.

Our second observation is that the classical demarcation lines between investment and speculation fail to capture the basic logics of economic activities under uncertainty. A main reason for the lack of clarity between the two concepts is that the demarcation often refers to characteristics that are not inherent to the actions, such as the duration of the decision and preparation costs, but rather describe its circumstances. Another inconsistency is that the difference between risk and uncertainty is often drawn incorrectly. Many economic actions are labelled as high-risk, although uncertainty in these cases cannot be quantified mathematically. The last—and by far the most relevant - problem, is that many authors draw a distinction between speculation and investment which is based on normative considerations such as the idea of an underlying interest and added value to the economy. In these cases, the definition of speculation and investment naturally depends on the normative fundament of the observer. Therefore, a clear and commonly understood separation between investment and speculation appears to be missing.

As we were unable to separate investment and speculation, we come to the conclusion that all actors, whether on Wall Street or Main Street, are involved in economic activities under uncertainty. Putting money into stocks or not being involved in financial markets at all are both speculative actions. Acknowledging this fact is, in our view, a major precondition for tackling the ethics economic activities under uncertainty, as a consistent terminology is helpful for building the fundament of normative assessments.

Based upon our contribution, we detected further need for research. The implications of the ethical judgement of different economic activities are still unclear and we need more knowledge in terms of the impact of language on decisions in financial markets and in ethical judgements. Moreover, it would be relevant to uncover the patterns of defining commercial action as "investment" or speculation". How do individuals and non-professionals come to the conclusion that a particular action is "investment" or "speculation"? Is the individual classification scheme primarily based on political preferences, profession or other personal factors? In the future, the input generated by this type of research might also give a benefit to the debate on discourse theory and the use of language for dealing with economic activities in general. Interesting and relevant questions in this direction would include the influence of language on the economic discourse in general and might add to the research field of narrative economics.

\section{Acknowledgments}

\section{Disclosure of Potential Conflicts of Interest}

The authors declared no potential conflicts of interest with respect to the authorship and/or publication of this article.

\section{Research Involving Human Participants and/or Animals}

This chapter does not contain any studies with human participants or animals performed by any of the authors.

\section{Funding}

The authors received no financial support for the research and/or authorship of this article. 


\section{References}

Allen, D. (1952). The nature of gambling. New York: Coward-McCann.

Angel, J., \& McCabe, D. (2009). The Ethics of Speculation. Journal of Business Ethics, 90(S3), 277-286. https://doi.org/10.1007/s10551-010-0421-5

Aristotle. (1920). Politics. In B. Jowett \& H.W. Davis (Eds.), Aristotle's Politics. Oxford: At the Clarendon Press.

Aristotle. (2009). The Nicomachean ethics (W. D. Ross \& L. Brown Eds.). Oxford: Oxford University Press.

Arthur, J. N., Williams, R. J., \& Delfabbro, P. H. (2016). The conceptual and empirical relationship between gambling, investing, and speculation. Journal of Behavioral Addictions, 5(4), 580-591. https://doi.org/10.1556/2006.5.2016.084

Arthur, T. (2000). Is the Stock Exchange a Casino? Economic Affairs, 20, 42-45. https://doi.org/10.1111/1468-0270.00256

Bogle, J. C. (2012). The Clash of the Cultures: Investment vs. Speculation. John Wiley and Sons.

Borna, S., \& Lowry, J. (1987). Gambling and speculation. Journal of Business Ethics, 6(3), 219-224. https://doi.org/10.1007/BF00382867

Brennan, J. F., \& Jaworski, P. (2015). Markets without Limits: Moral Virtues and Commercial Interests. Routledge. https://doi.org/10.4324/9781315818085

Bunia, R. (2013) Spekulation über Spekulation Zu Joseph Vogls Das Gespenst der Kapitals und zur Spekulation in den Geisteswissenschaften. In H. Pahl \& J. Sparsam (Eds.), Wirtschaftswissenschaft als Oikodizee? Springer VS, Wiesbaden. https://doi.org/10.1007/978-3-658-00126-1_9

Cato, M. P. (2014). De agricultura. In W. Hopper \& H. B. Ash (Eds.), On agriculture. Harvard University Press.

Cicero, M. T. (1913). De officiis. In W. Miller (Ed.), De Officiis. With an English translation by Walter Miller. London: William Heinemann. https://doi.org/10.4159/DLCL.marcus_tullius_cicero-de_officiis.1913

Emery, H. C. (1896). Speculation on the Stock and Produce Exchange of the United States. Studies in History, Economics and Public Law, 7(2).

Graham, B. (1958). The New Speculation in Common Stocks. The Analysts Journal, 14(3), 17-21. https://doi.org/10.2469/faj.v14.n3.17

Graham, B. (2009). The Intelligent Investor. Rev. Ed. Harper Collins.

Graham, B., \& Dodd, D. (1934). Security Analysis. Whittlesey House, McGraw-Hill Book Co.

Granero, R., Tarrega, S., Fernandez-Aranda, F., Aymami, N., Gomez-Pena, M., Moraga, S. L., ... Jimenez-Murcia, S. (2012). Gambling on the stock market: An unexplored issue. Comprehensive Psychiatry, 53(6), 666-673. https://doi.org/10.1016/j.comppsych.2011.12.004

Hazen, T. L. (2005). Disparate regulatory schemes for parallel activities: Securities regulation, derivatives regulation, gambling, and insurance. Annual Review of Banking \& Financial Law, 24, 375.

Holliday, J., \& Fuller, P. (eds.) (1974). The psychology of gambling. New York: Harper and Row Publishers.

IbnTaymiah, A. B. A. (1994). TafseerAa-yaat Ash-kelt. Maktabah Al-Rushd. Institutions.

Keynes, J. M. (1936). The General Theory of Employment, Interest and Money. London: Macmillan.

Knight, F. H. (1921). Risk, Uncertainty, and Profit. Boston, MA: Hart, Schaffner \& Marx.

Krugman, P. (2009). Taxing the Speculators. New York Times, Nov 26, 39. Retrieved from http://www.nytimes.com/2009/11/27/opinion/27krugman.html.

Luetge, C. (2015). Order Ethics or Moral Surplus: What holds a society together? Lanham, MD: Lexington.

Luhmann, N. (1991). Soziologie des Risikos. De Gruyter Studienbuch.

Lutzer, E. (2001). Seven Snares of the Enemy: Breaking Free from the Devil's Grip. Chicago: Moody Publishers.

Moura-Leite, R. C., Padgett, R. C., \& Galan, J. I. (2014). Stakeholder Management and Nonparticipation in Controversial Business. Business \& Society, 53(1), 45-70. https://doi.org/10.1177/0007650310395547

Murphy, M. J., \& Smolarski, J. M. (2018). Religion and CSR: An Islamic "Political" Model of Corporate Governance. Business \& Society, January 2018. https://doi.org/10.1177/0007650317749222

Neate, R. (2012). UBS trader accused of fraud 'lost £123k of own cash on spread betting’. Retrieved from 
https://www.theguardian.com/business/2012/sep/17/usb-trader-accused-fraud-spread-betting

Nell, M. (1990). Die Bedeutung des Risikos als Produktionsfaktor. Zeitschrift für die gesamte Versicherungswissenschaft, 79(1-2), 275-285. https://doi.org/10.1007/BF03189091

Radio New Zealand. (2018). Bankrupt builder imprisoned after gambling away \$1.5m. Retrieved from https://www.radionz.co.nz/news/national/359618/bankrupt-builder-imprisoned-after-gambling-away-1-poin $\mathrm{t}-5 \mathrm{~m}$.

Rawls, J. (1971). A Theory of Justice. Cambridge: Harvard University Press.

Risi, D. (2018). Time and Business Sustainability: Socially Responsible Investing in Swiss Banks and Insurance Companies. Business \& Society, May 2018, 1-31. https://doi.org/10.1177/0007650318777721

Sandel, M. J. (2013). The Moral Economy of Speculation: Gambling, Finance, and the Common Good. The Tanner Lectures on Human Values. University of Utah. February 27, 2013.

Schumpeter, J. A. (1942). Capitalism, Socialism and Democracy. London: Harper \& Brothers.

Shin, Y. C., Choi, S. W., Ha, J., Choi, J. S., \& Kim, D. J. (2015). Gambling disorder in financial markets: Clinical and treatment-related features. Journal of Behavioral Addictions, 4(4), 244-249. https://doi.org/10.1556/2006.4.2015.032

Sinn, H.-W. (1986). Risiko als Produktionsfaktor. Jahrbücher für Nationalökonomie und Statistik, 201(6), 557571. https://doi.org/10.1515/jbnst-1986-0602

Szado, E. (2011). Defining Speculation: The First Step toward a Rational Dialogue. Journal of Alternative Investments, 75-82. https://doi.org/10.3905/jai.2011.14.1.075

Tracey, E. (1932). Investment versus Speculation. The American Journal of Nursing, 32(1), 29-30. https://doi.org/10.1097/00000446-193201000-00006

Vogl, J. (2010). Das Gespenst des Kapitals. Diaphanes Verlag.

Volkogonov, D. (1994). Lenin. A New Biography. New York: Free Press.

Wahl, P. (2008). Food Speculation. The Main Factor of the Price Bubble in 2008. World Economy, Ecology \& Development. Berlin. Germany.

Watson, J. D. (2012). Foreword. In C. K. Fred (Ed.), Why You Win or Lose: The Psychology of Speculation. Courier Corporation.

Weber, M. (1976). The protestant ethic and the spirit of capitalism. New York: Charles Scribner's Sons.

Williams, R. J., Volberg, R. A., Stevens, R. M. G., Williams, L. A., \& Arthur, J. N. (2017). The Definition, Dimensionalization, and Assessment of Gambling Participation. Report prepared for Canadian Consortium for Gambling Research.

Yeo, J. (2017). Warren Buffett: The Difference between Investing, Speculating and Gambling. Retrieved from https://www.smallcapasia.com/warren-buffett-difference-between-investing-and-gambling/

\section{Copyrights}

Copyright for this article is retained by the author, with first publication rights granted to the journal.

This is an open-access article distributed under the terms and conditions of the Creative Commons Attribution license (http://creativecommons.org/licenses/by/4.0/). 